\title{
An Experimental and Economic Study of room heating through Solar Evacuated Tube Collector
}

\author{
Digvijay Singh ${ }^{1}$, S.P. Singh ${ }^{1}$, Mandar Agnihotri ${ }^{1}$, Kishore Palley ${ }^{1}$, A.K. Singh $^{2}$ \\ ${ }^{1}$ School of Energy and Environmental Studies (SEES), Devi Ahilya University, Indore, 452001, India \\ ${ }^{2}$ Central Arid Zone and Research Institute (CAZRI), Jodhpur, 342001, India \\ Email:digvijaysingh019@gmail.com ${ }^{1,}$ spsanjali@gmail.com ${ }^{1}$, mandaragnihotri101@gmail.com ${ }^{1}$, \\ Palleykishore@gmail.com ${ }^{1}$, akcazri@yahoo.com ${ }^{2}$
}

\begin{abstract}
An innovative solution of room heating investigated here was performed via Solar Evacuated Tube Collector (SETC). The performance of the system was found to be good with Coefficient of Performance (COP) above 5, for December. SETC along with heat exchanger acts as a heat source for the room, free heating during evening and night enabling the same heating effect to be delivered with $25 \%$ of energy consumption of an electric blower. The economic evaluation of the system has internal rate of return (IRR) of $66.7 \%$ and the payback period of 1.86 yrs when the system was used for 100 days for room heating and as water heater for 200 days. The economic attributes of the system revealed its economic viability.
\end{abstract}

Keywords-Room heating; solar evacuated tube collector; Coefficient of Performance (COP); Economic attributes

\section{INTRODUCTION}

Space heating is a common practice with different heating methods such as floor heating, wall heating, ceiling heating, air collector, storage bed for providing thermal comfort for humans as well as for other purpose like crop drying performed by Ploskić and Sture Holmberg (2014) [1], Maivel and Jarek (2014) [2], Singh et al.(2017) [3], and also through PCM energy storage techniques explained by Tyagi and Buddhi (2005) [4].The building sector accounts for around $40 \%-50 \%$ of energy consumption in developing countries over $30 \%$ of $\mathrm{CO}_{2}$ emission. In India the domestic consumption of electricity is $23.8 \%$ of the total distribution of electricity as per the energy statics report from Ministry Of Statistics, Government of India [5].The practice of space heating will reduce the dependency of energy on conventional grid. The author Mosallat et al. [6] developed a model in MATLAB and Simulink of the system consisting of solar flate plate collector and thermal storage tank for space heating using glycol as a cooling agent, the obtained results are compared with RET Screen software. In this paper, the performance of SETC for the room heating has been evaluated. The experimental investigations of the system were conducted in a classroom with a floor area of $30 \mathrm{~m}^{2}$ and ceiling height of $3 \mathrm{~m}$ along with symmetrical ventilation ducts on top of the north wall, at the Devi Ahilya University. The room is equipped with heat exchanger combined with SETC which act as a heat source as shown in Fig. 1. Here the heating is provided with the help of SETC having the capacity of 100 liters. The hot water brought into the room cavity with the help of PVC pipes having thickness of $3 \mathrm{~mm}$. The testing room is $3.35 \mathrm{~m}$ below the roof where the solar water heater is installed. The hot water from SETC is allowed to pass into the cross flow heat exchanger i.e., radiator. A $40 \mathrm{~W}$ electric fan is installed at the back side of the radiator in order to increase the rate of heat transfer, the room is insulated properly and doors are kept closed during the testing period.

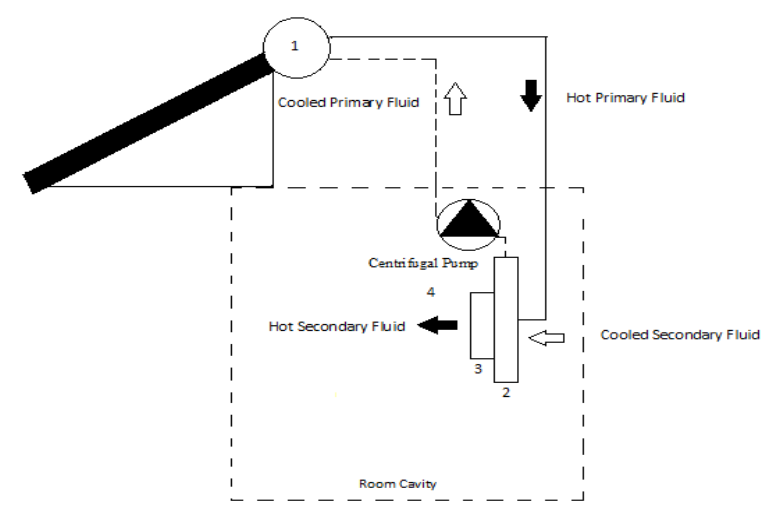

Fig. 1. Schematic of solar building heating system 1. SETC with heat storage tank, 2. Heat Exchanger 3. DC fan, 4. Centrifugal pump

\section{PERFORMANCE OF THE SYSTEM}

System performance has been calculated by following mathematical relations described by Cengel (1997) [7]

a) Water side

$$
q=\dot{m} c_{p} \Delta_{T}
$$




\section{Available online at www.ijrat.org}

\section{Coefficient of Performance (COP)}

It's defined as the ratio between useful thermal energy

$\left(\mathrm{E}_{\mathrm{t}}\right)$ and the input electrical energy $\left(\mathrm{E}_{\mathrm{el}}\right)$

$$
\begin{aligned}
& \operatorname{COP}_{\text {System }}=E_{t} / E_{\text {el }} \\
& \operatorname{COP}_{\text {System }}=\dot{\mathrm{m}} \mathrm{c}_{\mathrm{p}} \Delta_{\mathrm{T}} / \text { Total Work input }
\end{aligned}
$$

Where:

Total work input $=$ Fan power + Pump power

\section{b) Air side}

From Eq. (1)

Where:

$$
q=\dot{m} c_{p} \Delta_{T}
$$

$$
\dot{m}=A_{H} \times \rho_{a} \times V_{a}
$$

Table.1 System characteristics and performance

\begin{tabular}{|l|l|}
\hline System characteristics & \multicolumn{1}{|c|}{ Rating } \\
\hline DC Fan Power & $0.40 \mathrm{~kW}$ \\
\hline Centrifugal Pump Power & $250 \mathrm{~kW}$ \\
\hline Total Input Power & $0.29 \mathrm{~kW}$ \\
\hline $\begin{array}{l}\text { Total heat dissipation in } \\
\text { room }\end{array}$ & $5583.81 \mathrm{~kW}$ \\
\hline Total heat dissipation rate & $1.6 \mathrm{~kJ} / \mathrm{hr}$ \\
\hline COP $_{\text {system }}$ & 5.34 \\
\hline
\end{tabular}

\section{RESULTS}

The Fig. 2 represents the inlet and outlet water temperature, showing maximum inlet water temperature of $47.9{ }^{\circ} \mathrm{C}$ in the evening time, during winter (December).Fig. 3 compares the COP of both air and waterside in the radiator, it is found that COP of water side is greater than that of airside. Fig. 4 shows relation between output water temperature and room temperature. Fig. 5 shows relation between outlet water temperature and room temperature. Fig. 6 shows the heat supplied by SETC through the radiator which is $1.73 \mathrm{~kW} / \mathrm{hr}$ for December

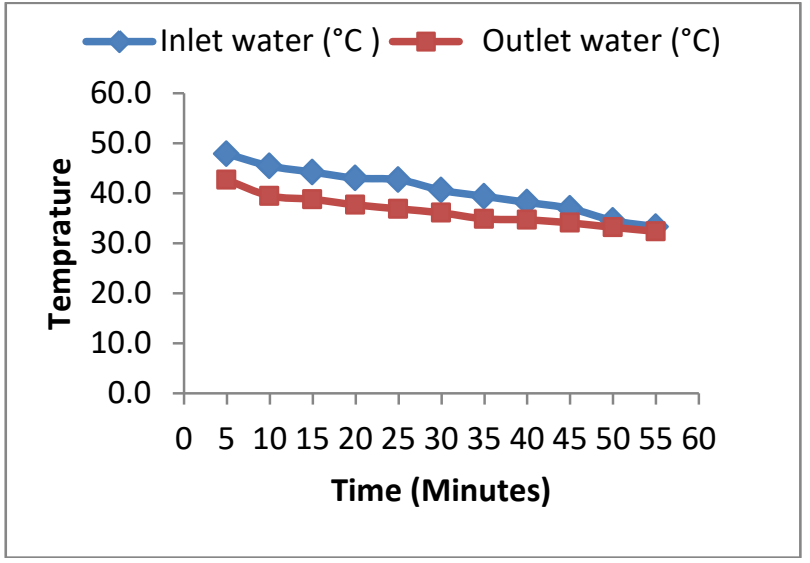

Fig. 2.

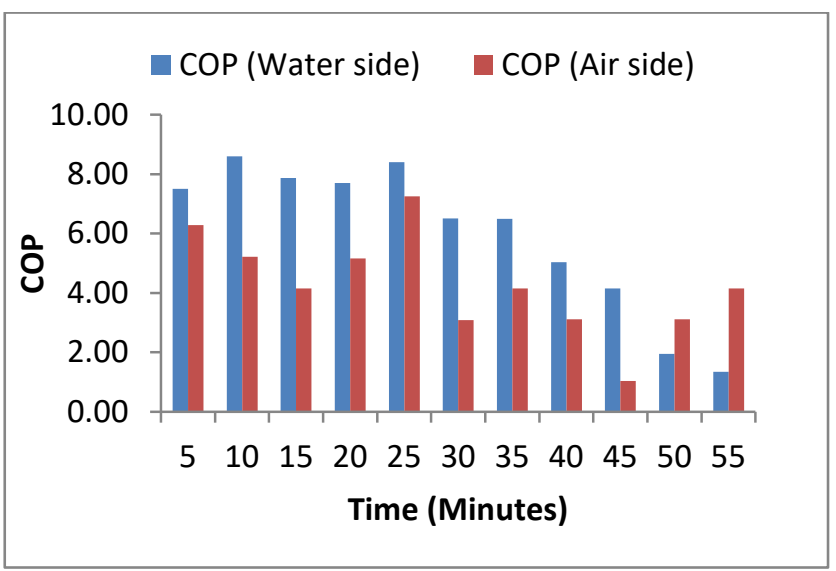

Fig. 3.

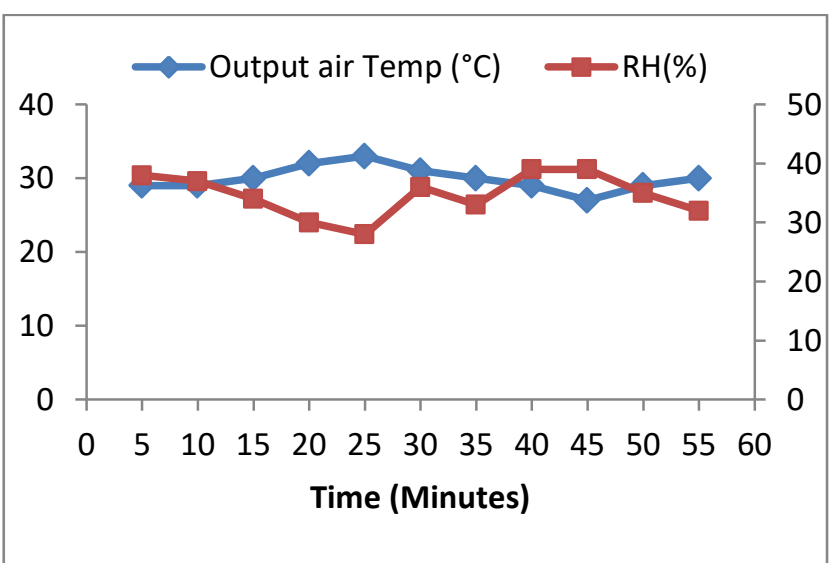

Fig. 4. 


\section{Available online at www.ijrat.org}

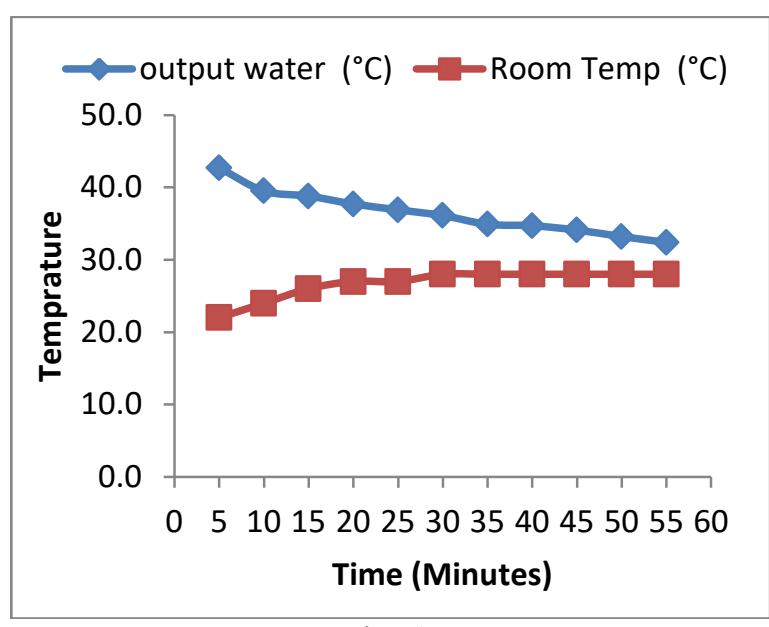

Fig. 5.

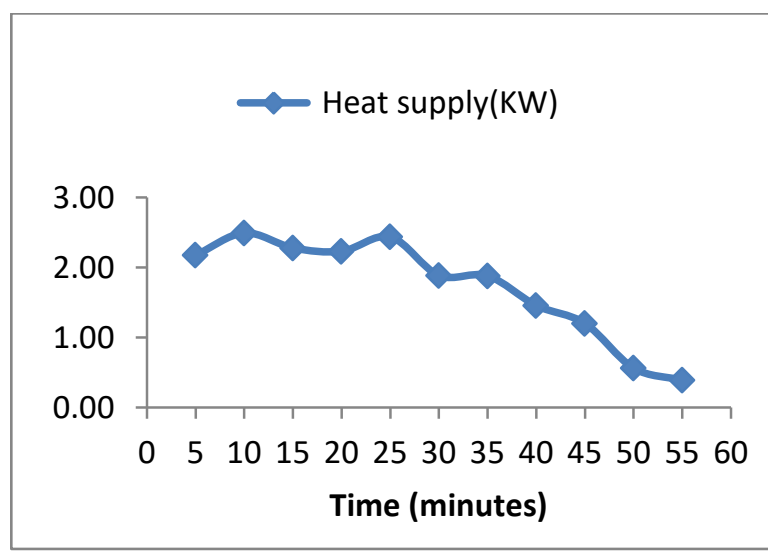

Fig. 6.

\section{ECONOMIC ANALYSIS}

The economic analysis of the present system was carried out by computing the Life Cycle Cost (LCC) and Life Cycle Benefit (LCB) of the unit. In addition, five economic attributes calculated by Singh et al. (2017) [8] and Poonia et al. (2018) [9] namely, Benefit-Cost Ratio (BCR), Net Present worth (NPW), Annuity (A), Internal Rate of Return (IRR) and Pay Back Period (PBP) were also determined for judging the economic viability of the system.

Table.2 Cost estimates of solar heating unit-

\begin{tabular}{|l|l|l|}
\hline $\begin{array}{c}\text { ITEM with } \\
\text { specification }\end{array}$ & Quantity & Amount \\
\hline Solar ETC & 1 & 10000 \\
\hline Radiator & 1 & 2000 \\
\hline Pump (250 W) & 1 & 1500 \\
\hline Fan (40 W) & 1 & 700 \\
\hline Pipe and joints & 4 & 1000 \\
\hline Teflon tape & 4 & 200 \\
\hline Total & & 15400 \\
\hline
\end{tabular}

\section{Economic attributes:}

- BCR: The ratio of discounted benefits to the discounted values of all costs given as LCB/LCC

- NPW: It is the sum of all discounted net benefits throughout the project given as LCB-LCC

- The annuity (A) of the project indicates the average net annual returns given as,

$$
(\text { Annuity })=\frac{N P W}{\sum_{t=1 \text { to } 10} 1 /(1+i)^{n}}
$$

- IRR: It is that rate of interest which makes life cycle benefits and life cycle cost equal $(\mathrm{LCB}-\mathrm{LCC}=0)$, can also be written as :

IRR=Lower discount rate + (difference of discount rate) $\times \mathrm{NPV}$ at lower discount rate / (NPV at lower discount rate - NPV at higher discount rate)

- $\quad$ PBP: It is the length of time from the beginning of the project before the net benefits return the cost of capital investments (value $\mathrm{n}$ for LCB - LCC = 0)

Determination of (LCC) and economic attributes: Economics of the system was calculated through life cycle cost (LCC) analysis. Let $\mathrm{P}_{\mathrm{i}}$ is an initial investment (Rs.), $\mathrm{P}_{\mathrm{w}}$ is operational and maintenance expenses including labour and machineries (Rs.), $\mathrm{n}$ are the life of the system. The procedure of life cycle cost estimation as adopted by Sodha et al. (1991) [10] and Barnwal and Tiwari et al. (2008) [11].

LCC $=$ Initial cost of land lease $\left(\mathrm{P}_{\mathrm{i}}\right)+\mathrm{P}_{\mathrm{W}}($ Annual $\mathrm{O} \&$
$\mathrm{M}$ Costs including electricity bill $))$

$\mathrm{LCC}=15400+1000 \times X\left(1-X^{15}\right) /(1-X)-1000 \times 1.1^{15}$ $=22761.9$

$X=\frac{1+e}{1+i}=(1+0) /(1+0.1)=0.909$

$\mathrm{LCB}=11100 \times \frac{X\left(1-X^{15}\right)}{(1-X)}=85284$

Where, $\mathrm{e}=$ annual escalation in cost (in fraction) $i=$ interest or discount rate (in fraction), $\mathrm{P}=15400$, Salvage Value $(\mathrm{SV})=\mathrm{Rs} 1000$, operation and Maintenance $(\mathrm{O} \& \mathrm{M}) \quad \operatorname{cost}=0.29 \mathrm{kWh} \times 5$ hours $\times$ 100 days $\times$ Rs 6 a unit $=$ Rs 870 , including cost of the tubes etc annual O\&M cost is about Rs 1000

As a water heater from Eq. (1)

Alternately,

$$
\begin{gathered}
\boldsymbol{q}=\dot{\boldsymbol{m}} \boldsymbol{c}_{\boldsymbol{p}} \boldsymbol{\Delta}_{\boldsymbol{T}} \\
q=18900 \mathrm{~kJ}
\end{gathered}
$$$$
18900 \mathrm{KJ}=5.25 \mathrm{kWh}
$$

Output as a water heater $=5.25 \times 6$ hours $\times 200$ days $=$ Rs 6300 and output as a room heater $=1.6 \mathrm{kWh} \times 5$ hours $\times 100$ days $\times$ Rs 6 a unit $=$ Rs 4800 


\section{Available online at www.ijrat.org}

Gross benefit: Rs 6300+ Rs $4800=$ Rs 11100

Table.3. Values of NPW for different rates of discount/interest (i)

\begin{tabular}{|c|c|}
\hline NPV & Interest rate $(\%)$ \\
\hline 62466 & 10 \\
\hline 4800 & 50 \\
\hline-987.3 & 70 \\
\hline
\end{tabular}

Table.4. Economic attributes of room heating system

\begin{tabular}{|l|l|}
\hline Attributes & Value \\
\hline NPW & 62466.1 \\
\hline BCR & 3.75 \\
\hline A & 8133.6 \\
\hline PBP & 1.86 \\
\hline IRR & 66.7 \\
\hline
\end{tabular}

\section{CONCLUSION}

A solar evacuated tube collector system is coupled with the radiator for room heating application of a class room in Indore, India. The experimental results of the system were examined for the month of December.

The rate of heat transfer of SETC to room via radiator is $1.5 \mathrm{KW} / \mathrm{hr}$ which was found in good agreement when compared with electric heater.

This system can be used during evening and night time for space heating, especially in remote areas where availibity of electricity is rare, to maintain the comfort level in their dwellings. The system is cost effective and feasible with the payback period of 1.86 yrs, but requires more reliability to meet demand fluctuations.

\section{REFERENCES}

[1] Ploskić, Adnan, and Sture Holmberg. "Performance evaluation of radiant baseboards (skirtings) for room heating-An analytical and experimental approach." Applied Thermal Engineering 62.2 (2014): 382-389.

[2] Maivel, Mikk, and Jarek Kurnitski. "Low temperature radiator heating distribution and emission efficiency in residential buildings." Energy and Buildings 69 (2014): 224236.

[3] Singh, D., Singh, A. K., Singh, S. P., \& Poonia, S. (2017). Year Round Potential of Greenhouse as
a Solar Dryer for Drying Crop

Produce. Agricultural Engineering Today, 41(2), 29-33.

[4] Tyagi, V. V., \& Buddhi, D. (2007). PCM thermal storage in buildings: a state of art. Renewable and Sustainable Energy Reviews, 11(6), 11461166.000

[5] Energy Statistics 2017, Ministry Of Statistics and Programme Implementation Government ofIndia.http://www.mospi.nic.in/sites/default/files/ publication_reports/Energy_Statistics_2017r.pdf.p $\underline{\mathrm{df}}$

[6] Mosallat, F., ELMekkawy, T., Friesen, D. L., Molinski, T., Loney, S., \& Bibeau, E. L. (2013). Modeling, simulation and control of flat panel solar collectors with thermal storage for heating and cooling applications. Procedia Computer Science, 19, 686-693.

[7] Cengel, Y. A. (1997). Introduction to thermodynamics and heat transfer (Vol. 846). New York: McGraw-Hill.

[8] Singh, D., Singh, A. K., Singh, S. P., \& Poonia, S. (2017). Economic Analysis of Parabolic Solar Concentrator Based Distillation Unit. Indian Journal of Economics and Development, 13(3), 569-575.

[9] Poonia, S., Singh, A. K., \& Jain, D. (2018). Design development and performance evaluation of photovoltaic/thermal (PV/T) hybrid solar dryer for drying of ber (Zizyphus mauritiana) fruit. Cogent Engineering, 5(1), 1-18.

[10] Sodha, M. S., Chandra, R., Pathak, K., Singh, N. P., \& Bansal, N. K. (1991). Techno-economic analysis of typical dryers. Energy Conversion and Management, 31(6), 509-513.

[11] Barnwal, P., \& Tiwari, G. N. (2008). Grape drying by using hybrid photovoltaic-thermal $(\mathrm{PV} / \mathrm{T})$ greenhouse dryer: an experimental study. Solar energy, 82(12), 1131-1144. 